\title{
PREDATOR MITE APPLICATION METHODS FOR BIOLOGICAL CONTROL OF TWO-SPOTTED MITES IN HOPS
}

\author{
P.W. SHAW and D.R. WALLIS \\ HortResearch, PO Box 220, Motueka 7143, New Zealand \\ Corresponding author: pshaw@hortresearch.co.nz
}

\begin{abstract}
The efficacy of a novel 'air stream' predator mite application method for the control of two-spotted mites (TSM, Tetranychus urticae) in hops was compared with a standard teaspoon release method. Predator mites (Phytoseiulus persimilis) were successfully established with a single release using both application methods and TSM declined to low numbers during the monitoring period. Application of predator mites with a delivery device attached to a conventional leaf blower mounted on a quad bike was equally effective and at least four times faster than hand application. There was no evidence of any physical damage to mites applied with the mite blower device. The potential of the 'air stream' application method to improve the efficiency of biological control of TSM using predator mites is discussed.
\end{abstract}

Keywords: two-spotted mite, biological control, hops, predator mite, Phytoseiulus persimilis, application method.

\section{INTRODUCTION}

The two-spotted spider mite (TSM), Tetranychus urticae Koch (Acari: Tetranychidae), has a wide host range and is an important pest of ornamentals and commercial crops including hops (van de Vrie et al. 1972). The predatory mite Phytoseiulus persimilis Athias-Henriot (Acari: Phytoseiidae) is an important predator of TSM and inoculative releases have been used successfully to control TSM on hops in Australasia (Leggett 1987; McKinnon 1987). Shaw \& Wallis (2005) carried out trials in Nelson, New Zealand, to monitor the performance of $P$. persimilis, which were introduced to hop vines after releases of TSM. The predatory mites controlled the pest without any economic damage to the hops, even at high initial prey to predator release ratios of between 50 and 200:1.

Hop growers in New Zealand are fortunate that aphid pests and fungal diseases of hops found in other countries where hops are grown commercially are not present in New Zealand and the only pesticide they may have to apply are miticides to control TSM. Nelson is the only location in New Zealand where hops are grown commercially and TSM are usually a problem only during mild spring and hot dry summer conditions when they may colonise hop vines early in the season and rapidly increase in number (Harris-Virgin et al. 2004). In these situations, control measures may be necessary to prevent serious damage to the hops. The use of miticides can be harmful to predator mites and can result in chemical residues on the hops that are becoming a marketing issue (Doug Donellan, CEO New Zealand Hops Limited, pers. comm.). There is a niche market for 'spray free' hops that may expand in future. Biological control of spider mites provides a non-chemical control option, but to be effective, predator mites should be present as soon as, or shortly after, the pest mites colonise hop vines. Under natural conditions TSM colonise hop vines first in early summer, followed some time later by the predatory mites. This delay can allow TSM numbers to increase unchecked and can result in unacceptable crop damage before the predatory mites finally manage to contain the population. To avoid this risk, it is necessary for growers to monitor their crops and 
make inoculative annual releases of $P$. persimilis when TSM first appear on hops. In Nelson, this is typically during December. Predator mites are available commercially and supplied either on bean leaves or in vermiculite. Most hop growers now purchase predator mites in vermiculite and apply them to their crop by distributing them with a teaspoon onto the lower leaves of hop vines.

This paper describes the development and advantages of a novel mite blower device for the distribution of predator mites in hops and compares mite control achieved with this method and hand application.

\section{Comparison of release methods}

\section{METHODS}

Two methods for releasing predator mites were compared in a block of cv. Pacific Gem hops at the HortResearch Nelson Research Centre near Motueka. The standard teaspoon release method used by growers represented a control treatment that was compared with a system designed to release predator mites in an airstream. In each treatment there were four plots consisting of 10 vines (five vines each in two adjacent rows) arranged in a randomised block design. Each treatment plot within the block was spaced $12 \mathrm{~m}$ apart.

A pre-release mite count on 25 leaves collected randomly from the trial block was carried out on 12 December 2006 and six TSM and no predator mites were recorded. With such a low natural infestation, additional TSM on bean leaves were released on to the trial vines at a rate of approximately 500/vine on 13 December 2006 to ensure there were sufficient mites to conduct the trials. Predator mites supplied in vermiculite were applied to the trial vines using the two release methods at a rate of approximately five/vine on 19 December 2006. This provided an initial prey to predator release ratio of approximately 100:1. This ratio is considerably higher than would be expected in a grower block and was used experimentally to provide a rigorous test for the release methods. Mites were supplied by Zonda Resources Limited.

In the standard release treatment, half a teaspoon of vermiculite containing approximately five predator mites was applied to the lower leaves on each vine. In the 'air stream' treatment, a device for applying predator mites ('airbug', Koppert Biological Systems) (Fig. 1) was attached to a conventional motorised leaf blower that was mounted on a farm quad bike. A $300 \mathrm{ml}$ plastic bottle containing 500 predator mites in vermiculite was attached to the top of the 'airbug'. Mites were released through a small opening into the device and blown onto vines in each replicate as the quad bike was driven through the trial block. The speed of the leaf blower and quad bike was adjusted to deliver an estimated five predators/vine. Predator release rates in both treatments were equivalent to approximately 20,000 predators/planted ha.

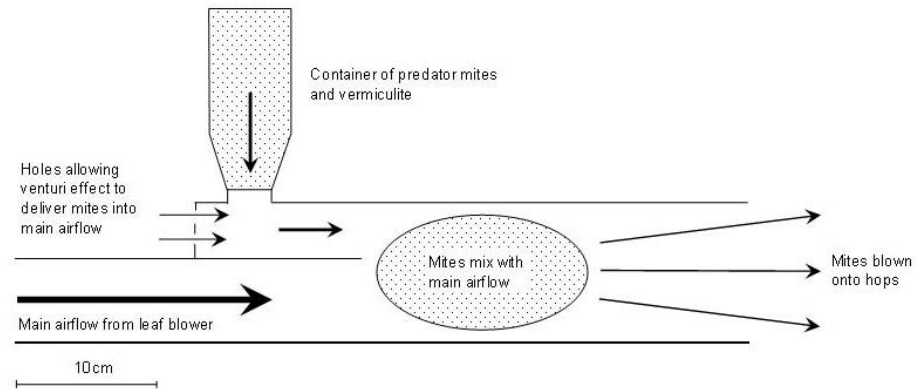

FIGURE 1: Schematic design of the mode of operation of the 'airbug' device that is attached to a leaf blower to enable predator mites to be blown onto hop vines. 
Twenty-five leaves were collected from each plot (100 leaves/treatment) on each of four occasions from 8 January 2007 to 21 February 2007. On each sampling date, the numbers of active stages of TSM and $P$. persimilis on the leaves were counted with the aid of a binocular microscope.

During testing of the 'airbug', predator mites blown from the device with the leaf blower were trapped on sticky cardboard bases laid out in a $5 \mathrm{~m}$ long line in front of the leaf blower. Predators caught on the bases were examined with a binocular microscope to determine if any were physically damaged.

\section{Application time trial}

In a separate trial to compare predator application times with the 'airbug' and teaspoon release methods, the time taken to cover an area of hops at a release rate equivalent to 8000 predators/ha, which is a typical release rate used by commercial growers, was recorded. To achieve this release rate the leaf blower was set at just above idle speed and the quad bike speed set at $7 \mathrm{~km} / \mathrm{h}$. This was compared with the time taken to apply predators in vermiculite with a teaspoon at the same release rate.

\section{RESULTS AND DISCUSSION}

Mite counts indicated there were similar numbers of spider mites and $P$. persimilis in both the teaspoon and 'airbug' release treatments on the first monitoring occasion on 8 January when peak numbers of TSM were recorded (Fig. 2). The prey to predator ratios on this date were 16:1 and 20:1, respectively, but numbers of TSM were under 10 active stages per leaf, a level which Strong \& Croft (1995) suggested as the economic threshold for this pest on hops. Some mite damage was observed on leaves in both treatments during the collection of the first sample on 8 January, which would indicate that TSM numbers may have peaked prior to this date.
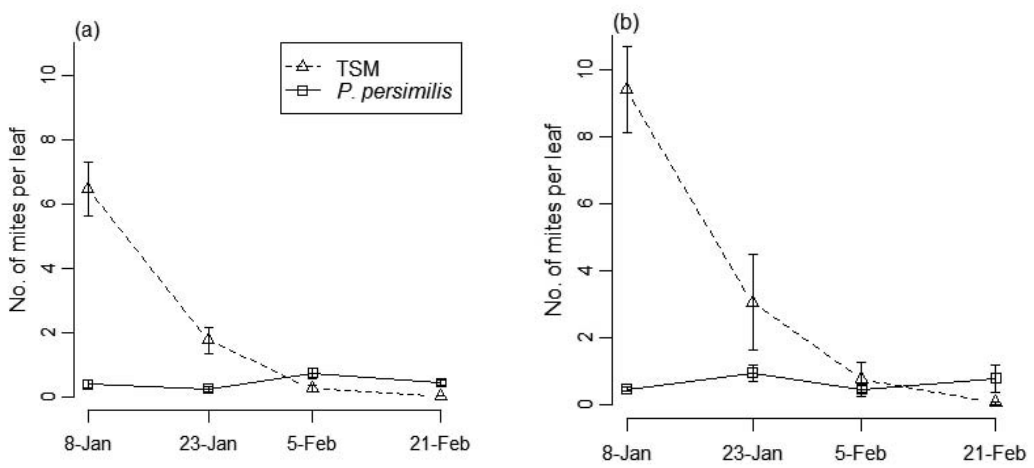

FIGURE 2: Mean number of two-spotted mites and $P$. persimilis per leaf recorded on four monitoring dates in $\mathbf{2 0 0 7}$ with (a) predator mites in vermiculite applied with a teaspoon and (b) predator mites in vermiculite applied with the 'airbug' device on 22 December 2006. Vertical bars represent one standard error each way.

By 23 January, numbers of TSM had declined dramatically and by the final monitoring date on 21 February, just before harvest, very few remained. Numbers of TSM, which were released at the same initial prey to predator ratios in trials between 2004 and 2006 (Shaw \& Wallis 2005, 2006), did not increase to the same extent in the 2006-2007 trial, possibly because of cooler early summer conditions that slowed TSM development. Predator mites quickly reduced the TSM population and predator numbers remained 
static at approximately 1 or lower per leaf during the monitoring period as TSM numbers remained low on both treatments (Figs $2 \mathrm{a} \& 2 \mathrm{~b}$ ).

These results indicate that predator mites were successfully established with a single release using both application methods and TSM declined to low numbers during the monitoring period. The early release of predators to coincide with the appearance of TSM in the crop is an important factor for successful control of the pest (Campbell \& Lilley 1999). Hop growers should commence monitoring their crops for spider mites from late November to determine when releases of predator mites should be made.

The predator mite application time trial at a typical commercial release rate equivalent to 8000 predators/ha indicated that the 'airbug' mounted on the quad bike could distribute predators at this density over four hop rows in $1 \mathrm{~min} 41 \mathrm{~s}$ while only one row could be covered in the same time by walking down the row and applying predators in vermiculite with a teaspoon. This represents a 75\% saving in labour costs using the 'airbug' system. The increased application efficiency with the 'airbug' system will thus provide a costeffective alternative to hand application. The material cost for predator mites at release rates of 6000-8000/ha is similar to the cost of a miticide, so improved application efficiency with the 'airbug' system will provide growers with a practical non-chemical option for TSM control. Examination of predator mites $(n=50)$ blown from the 'airbug' and trapped on sticky traps over a distance of five metres showed that none appeared to be physically damaged.

Growers currently release predator mites on every fourth to eighth vine whereas the leaf blower and 'airbug' delivery system provides a continuous release of predators. This should ensure good spacial distribution of predator mites and it may be possible to reduce application rates without compromising control of TSM. A hop grower who used the application system to apply predator mites at a release rate of 5000/ha reported good predator mite establishment and control of TSM on his hop blocks (K. McGlashen, pers. comm.). Further testing of the 'airbug' release system on commercial hop blocks at different application rates is needed to confirm the effectiveness of the release method and help to determine cost-effective guidelines for biological control of TSM on hops with predator mites. The production of 'spray free' hops will maximise the market potential for the crop.

\section{ACKNOWLEDGEMENTS}

We thank Zonda Resources Limited for arranging shipment of the 'airbug' device and supplying mites for the trials. Funding for this research was provided through a Sustainable Farming Fund grant from the Ministry of Agriculture and Forestry.

\section{REFERENCES}

Campbell CAM, Lilley R 1999. The effects of timing and rates of release of Phytoseiulus persimilis against two-spotted spider mite Tetranychus urticae on dwarf hops. Biocontrol Science and Technology 9: 453-465.

Harris-Virgin PM, Wallis DR, Shaw PW 2004. Two spotted mite control in hops 2003 2004 season. HortResearch Report No. 13507. HortResearch, Auckland. 9 pp.

Leggett GW 1987. An investigation of the effect of release of the two-spotted mite predator, Phytoseiulus persimilis, on hops in Tasmania. Research Report No. 87-01, Australian Hop Marketers Proprietary Limited. 16 pp.

McKinnon L 1987. Attempts to establish control of two-spotted mite in hops using the predatory mite Phytoseiulus persimilis. In: Hop Research Report 1986/87 Season, Lewis GK ed. Carlton and United Breweries Limited, Melbourne, Victoria, Australia. Pp. 8-10.

Shaw PW, Wallis DR 2005. Sustainable hop farming: an investigation into mite control. HortResearch Report No. 15239. HortResearch, Auckland. 13 pp.

Shaw PW, Wallis DR 2006. Sustainable hop farming: an investigation into mite control. HortResearch Report No. 15247. HortResearch, Auckland. 10 pp. 
Strong WB, Croft BA 1995. Inoculative release of phytoseiid mites (Acarina: Phytoseiidae) into the rapidly expanding canopy of hops for the control of Tetranychus urticae (Acarina: Tetranychidae). Environmental Entomology 24: 446-453.

van de Vrie M, McMurtry JA, Huffaker CB 1972. Ecology of tetranychid mites and their natural enemies: a review. III. Biology, ecology, and pest status, and host-plant relations of tetranychids. Hilgardia 41: 343-432. 